\section{NEW APP FOR BRITISH DENTAL CONFERENCE 2015}

Delegates at this year's British Dental Conference and Exhibition will find everything they need at the tip of their fingers thanks to a new app specially designed for the event. A first for 2015, the app is suitable for both Apple and Android devices and makes managing your time at the event and getting around even easier than before. The app is available to download now via the Apple App Store or Google Play.

Key features of the new app include:

- A personal agenda feature allowing delegates to browse full programme information and add sessions they would like to attend to their own personalised event diary

- Full speaker bios

- Venue and exhibition maps

- Instant event notifications

- Access to special show offers

- Visitor information from cash machine locations to car parking

- Direct access to Twitter and Facebook allowing users to interact and share views with other delegates and organisers

- Notes section that allows you to save and email notes to yourself.

Linda Stranks, Director of Marketing and Membership at the British Dental Association (BDA), said: 'We have designed this app to make the event experience as simple and exhibitors.' members in mind.

\section{Dental nurses} pathways. smooth as possible. Many of our delegates now carry smartphones so it makes sense to interact with them and provide show information directly into their hands. We want to make the event even more interesting for visitors and more interactive for

This year's event will take place from 7-9 May at the Manchester Central Convention Complex with many of the sessions of interest to the whole team. However, in addition, there are also a number of sessions which have been designed with particular team

One session that's not to be missed is the Career Pathways presentation in the Training Essentials theatre (Friday, 12 noon). In this special session for dental nurses, BADN President Fiona Ellwood will look at the opportunities that are out there for dental nurses. She will help dental nurses reflect on developing as a specialist practitioner and consider what a new dental contract might mean for dental nurses' future career

\section{Dental hygienists and therapists}

On Friday morning the BSDHT is hosting a must-attend Conference Pass session at which Paul Brocklehurst, Senior Clinical Lecturer/ Honorary Consultant, Dental Public Health and NIHR Clinician Scientist, University of Manchester will be looking at the evidence supporting the use of dental hygienists and therapists in primary care. Another highlight for dental therapists is the Paediatric Prevention presentation in the Training Essentials theatre (Saturday, $11 \mathrm{am}$ ) in which Amanda Gallie, Dental Hygienist and Therapist, and DCP Advisor,

Health Education England (East Midlands) will look

at systems for developing a child friendly hygiene and

therapy practice. In total the Training Essentials theatre offers 19 x 30-minute sessions based on the BDA's Training Essentials portfolio. Topics include dealing with emergencies, radiation doses in dental radiography, child and adult safeguarding, infection control and team working.

\section{Practice managers and administrators}

One highlight that's not to be missed is the ADAM team leadership presentation in the Training Essentials theatre (Thursday, 4 pm). In this special session Association Honorary Vice President Tracy Stuart will walk through the steps of building a team rather than a group of people that turn up to the same place of work each day. She will help you understand the many hats you need to wear as a business owner or manager. She will share the changes in marketing, what is working and what isn't and how you can convert calls into patients and treatment plans into solutions the patients wants to pay for without becoming an aggressive sales person.

Further event highlights include a large exhibition featuring the live Demonstration theatre, Speakers' corner and Innovation zone, free advice sessions with BDA advisors and an evening social programme including networking drinks, a Cuban party night. Up to 15 hours' CPD will be on offer with all core CPD subjects covered.

Conference Passes for dental care professionals offer great value with a one day Conference Pass priced at $£ 95$ and a full three day Conference Pass just $£ 155$. This gives you access to all the lectures as well as the shorter sessions in the Exhibition Hall.

Alternatively, you could attend the event free of charge by registering for your FREE Exhibition Pass which gives you access to the shorter Training Essentials theatre sessions outlined above as well as the other Exhibition Hall sessions. Don't miss out!

Further programme information and booking details for both Conference and Exhibition Passes is available at www.bda.org/conference

Delegates can register online at www.bda. org/conference or by calling 08701666625 .

\section{Please note!}

The UK general election will take place on Thursday 7 May 2015. If you are planning to attend the event on this day and wish to vote in the election you will need to apply for a postal vote if you cannot attend your local polling stations.

\section{bdjteam201530}

Do you have a news story that you would like included in BDJ Team? Send your press release or a summary of your story to the Editor at bdjteam@nature.com. 